\title{
SPACE BIOPRINTER: RESET
} KOCMИЧЕСКИЙ БИOПPИНTEP:

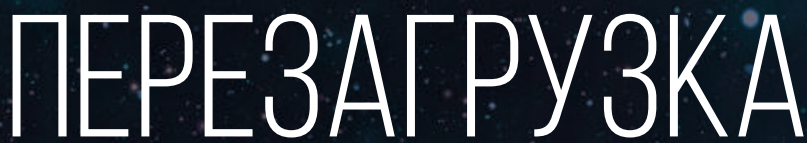

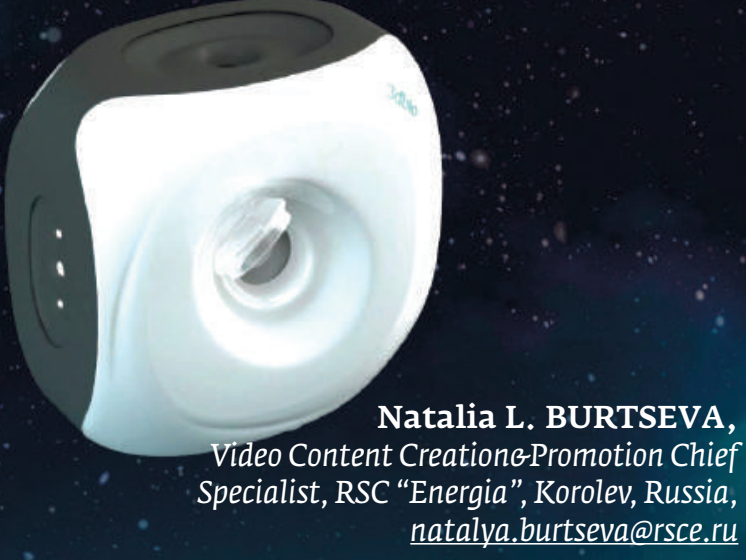

ABSTRACT I In October 2018 a unique experiment related to the problem of zero-gravity biotissue growth was to be carried out. The «3D-bioprinter» developed by Russian scientists and a biomaterial folding were loaded in the «Soyuz MS-10» spacecraft orbital module. But an emergency situation led to the serious deformation of the orbital module and, as a consequence, to the loss of the device. However, the engineers haven't rejected the research program and have produced a new flight printer. The experiment will start shortly after the crew of «Soyuz MS-11» is on the station. The «ASJ» correspondent has talked to the experts and cosmonauts about the details of the experiment.

Keywords: biotechnologies, biomaterial, zero-gravity, «3D-bioprinter» experiment
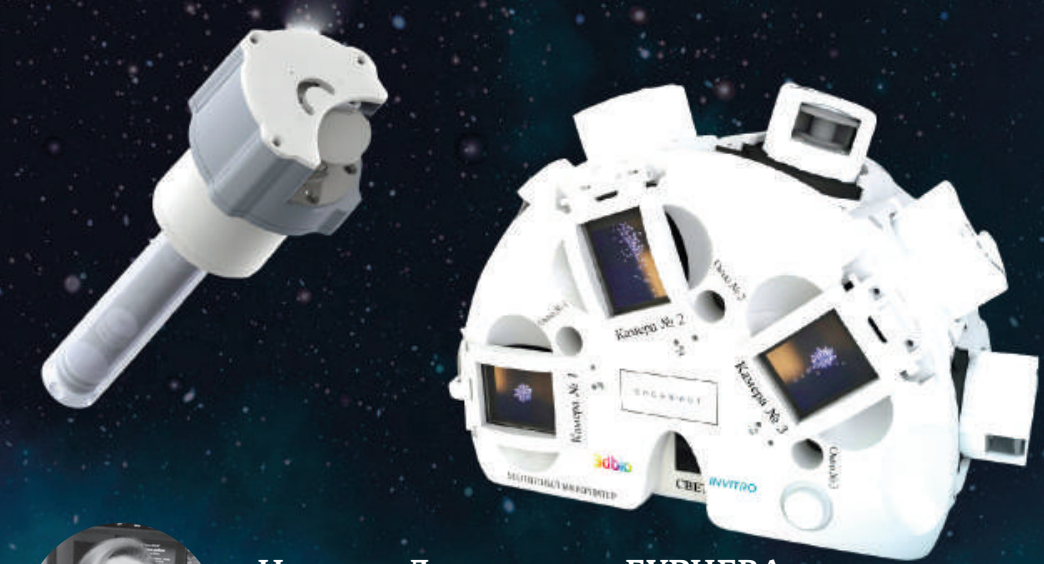

Наталья Леонидовна БУРЦЕВА, главный специалист по созданию и продвижению видеоконтента ПАО «РКК «Энергия», Королёв, Россия, natalya.burtseva@rsce.ru

АННОТАЦИЯ I В октябре 2018 года на МКС должен был начаться уникальный эксперимент по выращиванию биотканей в условиях невесомости. Разработанный российскими учеными «3D-6иопринтер» и укладки с биоматериалами были загружены в бытовой отсек космического корабля «Союз МС-10». Но аварийная ситуация привела к серьезной деформации бытового отсека и, как следствие, к потере прибора.

Однако разработчики не свернули научную программу, а произвели новый летный экземпляр принтера. Эксперимент начнется сразу после того, как экипаж «Союза МС-11» окажется на станции. Корреспондент «ВКС» побеседовал со специалистами и космонавтами о подробностях эксперимента.

Ключевые слова: биотехнологии, биоматериал, невесомость, эксперимент «3D-биопринтер» 


\section{Ученые считают эксперимент «3D-биопринтер» важсным}

\section{шагом на пути к решению проблемы создания донорских органов для человека.}

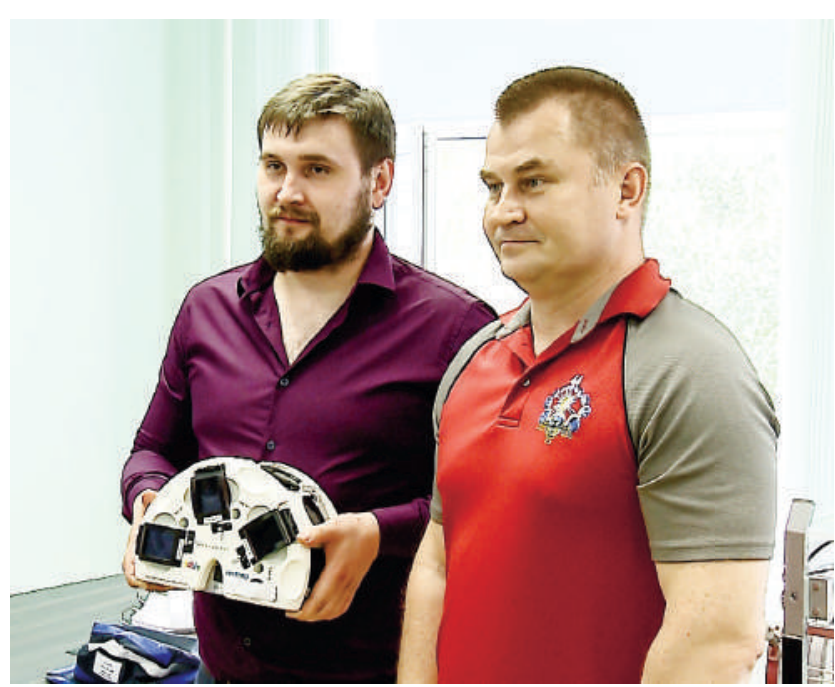

$\mathrm{H}$ а Земле ученые уже могут искусственно выращивать клетки, и даже целые органы животных. К примеру, биотехнологи «напечатали" щитовидную железу мыши.

Невесомость - уникальная среда, которая позволит произвести биоматериал лучшего качества, с большим количеством живых клеток.

Обычно только на подготовку подобного эксперимента уходят многие годы. Специалисты лаборатории 3D Bioprinting Solutions, ракетно-космической корпорации "Энергия", ЦНИИмаш и Центра подготовки космонавтов после 12 месяцев подготовительной работы над проектом рассчитывают реализовать его всего за полтора года.

Следует отметить, что разработанный прибор это не совсем принтер. Ему больше подошло бы название «биофабрикатор". В устройстве нет ни одной движущейся части, кроме открывающихся крышек видеокамер. Биоматериал здесь не печатается, а выращивается.

"3D-биопринтер" умещается на двух ладонях, а весит около 10 килограмм.

В специальных кюветах разместили клеточные сфероиды и парамагнетическую питательную среду. В условиях невесомости процесс слияния-сра-
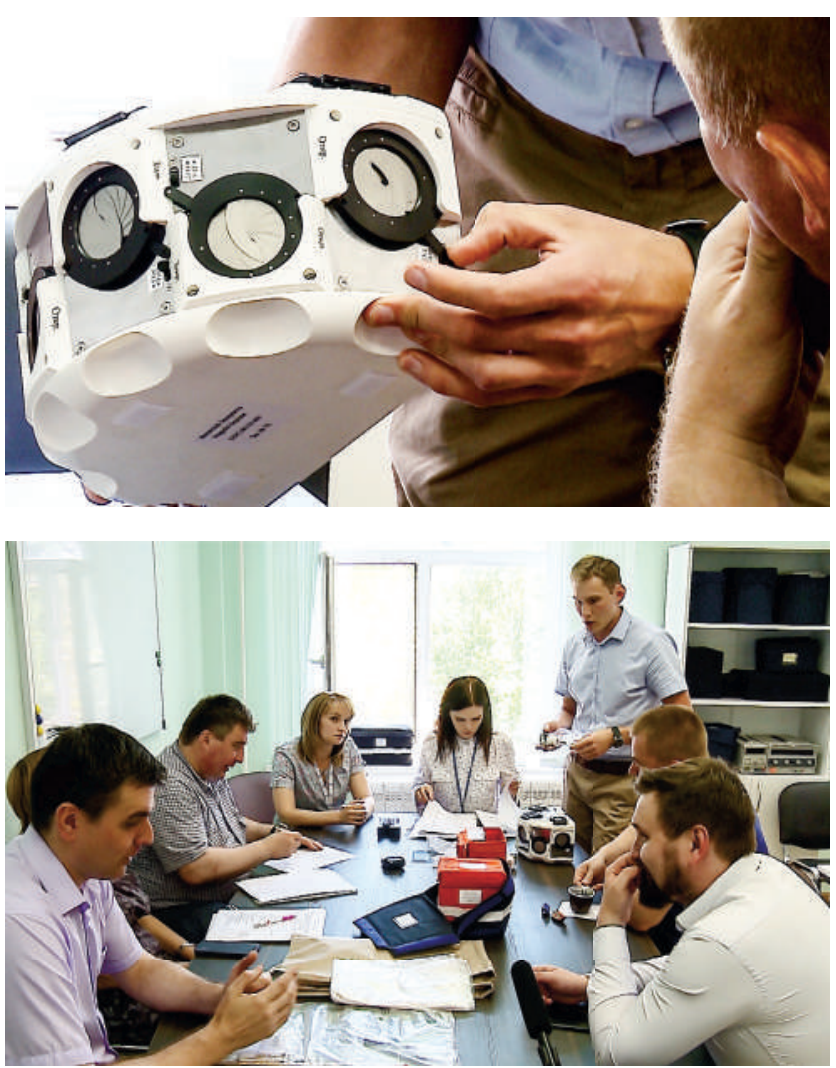

щивания клеток будет происходить без гравитационного сдавливания.

\section{Дмитрий СУРИН,} заместитель руководитеяя НТЦ РКК «Энергия»:

- Мы рассчитываем, что после завершения первого этапа эксперимента привезем из космоса образцы диаметром два-три миллиметра, только начавшие расти: хрящевую ткань и ткань щитовидной железы. На Земле образцы будут тщательно препарированы и исследованы, чтобы выбрать режим биофабрикации и продвинуться к следующему этапу.

Следующий этап - создание органа, например, щитовидной железы, или части сустава, или целого уха животного. Что именно это будет - время покажет.

С каждым шагом мы будем продвигаться к решению важной проблемы - созданию донорских органов для человека.

Кроме того, мы серьезно говорим о том, чтобы создавать с помощью принтера белковую пищу прямо на борту, то есть буквально растить котлеты в космосе. А это - шаг к созданию замкнутой системы жизнеобеспечения, необходимой для полетов к дальним планетам. 
ЦПК имени Ю. А. Гагарина. Тренировка экипажа. Специальный перчаточный бокс. Космонавт Олег Кононенко готовится к проведению эксперимента «3D-биопринтер». В космосе в специальных кюветах он будет выращивать биоткани.
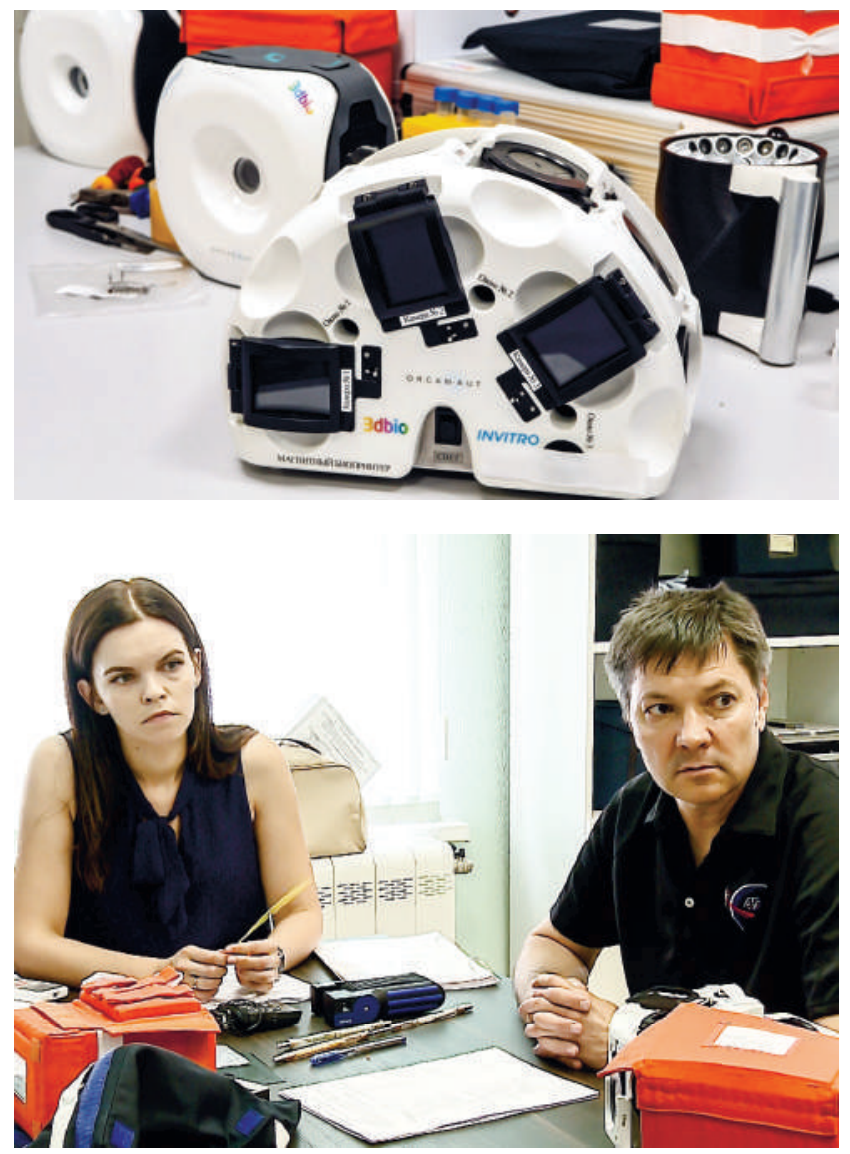

Алексей Овчинин, космонавт, Герой Российской Федерации:

- Я должен был начать этот новый эксперимент, но, к сожалению, мы не долетели до станции. Теперь эта честь выпадет Олегу Кононенко. Он уже готовился к эксперименту как командир дублирующего экипажа.

Биологические и биотехнологические эксперименты проводятся в каждом космическом полете. Но данное исследование - очень ожидаемая и перспективная премьера.

Ученые считают, что в космосе, в невесомости, процесс «производства» клеток и органов будет проще, выращенные ткани получат более правильную структуру, будут лучше работать и быстрее приживаться.

МКС - уникальная лаборатория. Все биологические эксперименты в космосе действительно удаются качественнее, чем на Земле - из-за отсутствия гравитации. Длительная невесомость способствует получению биообразцов с большим процентом жизнеспособных клеток.

Я считаю, что этим надо пользоваться.
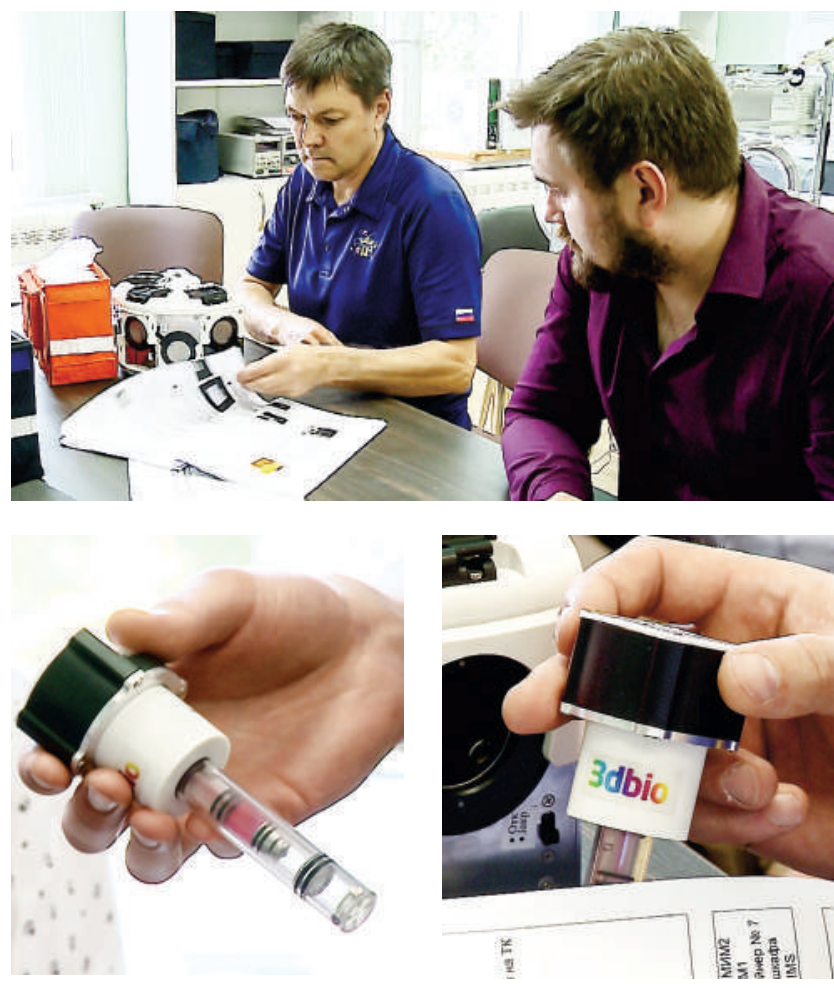

Как биопринтер будет работать в космосе

\section{Станислав ПЕТРОВ,} инженер-конструктор компании 3D Bioprinting Solutions, один из разработииков биофабрикатора:

- Сложно создать условия для отправки живых сфероидов, клеток на борт космической станции. При доставке, а особенно при возврате на Землю возникают большие перегрузки. Нестабильные температуры и множество других космических факторов сильно усложняли нам работу при создании системы. Но мы постарались, чтобы наша установка была надежна и максимально проста в управлении.

На орбите космонавты достанут две укладки - сам биопринтер и кюветы с образцами (всего 12 кювет для 6 экспериментов, плюс запасные - на случай, если что-то пойдет не так), разместят их в рабочем модуле МИМ-1, где есть вся необходимая аппаратура, в том числе термостаты. Далее извлекается оборудование, биопринтер устанавливается в космической лаборатории. У него есть специальные крепления типа велкро.

Космонавт нажмет на первый поршень и впрыснет в специальную кювету миллилитр питательной среды с солями парамагнетика. Для 
отработки технологии предусмотрена разная концентрация биоматериала: и такая, которая используется на Земле, и такая, которую мы сможем позволить себе только в космосе.

Затем космонавт включит камеры, освещение, установит кювету в принтер. Так начнется процесс сборки клеток.

Как только клетки соберутся в центре, прибор установят в термостат. В течение двух суток будет происходить инкубация при температуре $37^{\circ}$, чтобы клетки окончательно срослись.

Далее космонавт изымет биоматериал из термостата и впрыснет в него фиксатор - параформальдегид, который позволит приостановить рост клеток и сохранит их для изучения.

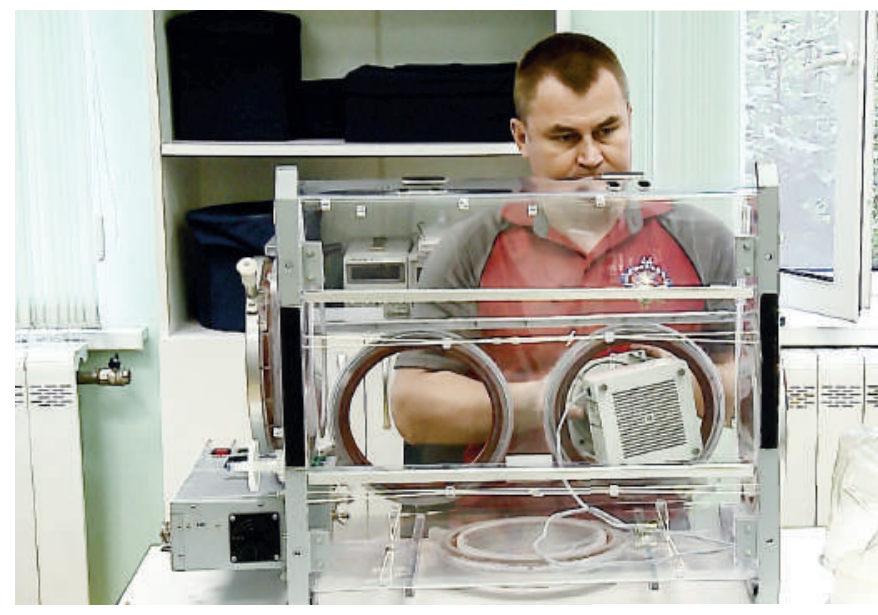

\section{ОлеГ КОНОНЕНКО, космонавт, Герой Российской Федерации:}

- Биологические эксперименты на борту МКС очень важная часть нашей работы. Космонавты служат на орбите глазами и руками ученых. За каждую экспедицию я и мои коллеги выполняем на борту от 10 до 15 таких экспериментов.

Наши усилия направлены на то, чтобы в дальнейшем обеспечить устойчивость человека $\mathrm{K}$ влиянию таких факторов, как невесомость, радиация. Это необходимо, если мы хотим и дальше осваивать космическое пространство.

Мы летаем на МКС с единственной целью: проводить исследования и выполнять научные эксперименты.

Сейчас мы провели полный цикл тренировок. Полностью отработаны этапы выполнения эксперимента в космосе. Для нас главное - все сделать по порядку и зафиксировать поведение микрочастиц в невесомости, а далее ученые будут анализировать возможности выращивания тканей в космосе.
В планах у разработчиков создать биопринтер большего размера, чтобы и экспонируемых материалов могло быть больше. Рассматривается даже возможность создания отдельного модуля на космической станции, где можно было бы выращивать органы, не повреждая клетки.

После завершения первого эксперимента по выращиванию тканей в условиях отсутствия гравитации на Землю в спускаемом аппарате вернется только укладка с кюветами. Сам биопринтер останется на орбите. Процесс выращивания биоматериала в космосе продолжится. Уникальная среда невесомость - поможет решению многих земных проблем.

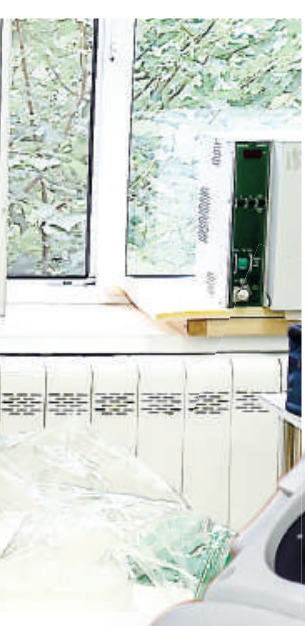

\section{Отсутствие}

гравитационного сдавливания позволяет производить в космосе биоматериал лучшего качества, нежели на Земле.

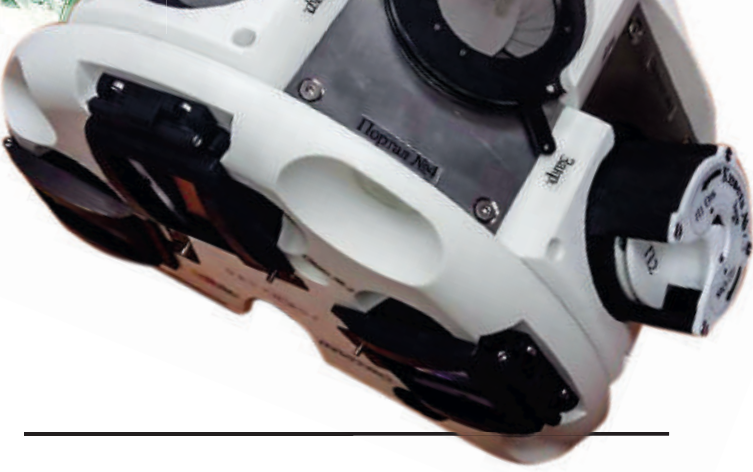

(С) Бурцева Н. Л., 2018

История статьи:

Поступила в редакцию: 27.10.2018

Принята к публикации: 19.11.2018

Модератор: Гесс Л. А.

Конфликт интересов: отсутствует

Для цитирования:

Бурцева Н. Л. Космический биопринтер: перезагрузка // Воздушно-космическая сфера. 2018. №4(97). C. 94-97. 